\title{
URGENT ISSUES AND MODERN CHALLENGES OF HIGHER EDUCATION
}

\author{
Yurii Pelekh \\ Rivne State University of Humanities, Ukraine \\ E-mail: pelekhyurii@ukr.net
}

\begin{abstract}
Modern society, which is experiencing dynamic changes due to the new global challenges, is definitely looking for solutions in science and education. The life of many generations has proved that no matter what problems humanity faces, their solution requires intellectual effort, a scientific approach and a quality education system as one of the most effective means of disseminating ideas, knowledge and values.
\end{abstract}

At the same time, such a situation always leads to the thorough attention to the phenomenon of education, in particular higher education. Great expectations and hopes cause significant demands and fundamental tasks that the society puts forward to the academic community. Satisfaction of these requirements and the solution of such tasks is probably not possible without self-analysis and self-reflection, without identifying those problems that inhibit the development of education itself, decrease its functionality, and discredit its status as the spiritual basis of social life. Therefore, we will further try to formulate our vision of current issues and current challenges in higher education.

First, we focus on the educational problem, which, so to speak, belongs to the eternal category - the problem of the content of education. This issue is relevant both for the academic community and for the society as a whole. Consideration of this issue in different periods led to the creation and establishment of different educational paradigms (for example, education as a means of forming a scientific picture of the world; education as a space of professionalization; education as a way of forming a culture of mental activity, etc.). In recent decades, the concept of education as preparation for life has become increasingly popular. Such education encourages self-development, development of intellectual abilities and creativity, motivates lifelong learning, and affirms the paradigm of openness to the new, innovative, and "fresh" content. However, there is an obvious question: How is this concept reflected in the modern educational space and more specifically, in certain educational programs?

In turn, the implementation of the concept of education as preparation for life greatly increases the requirements for the teaching staff regarding professional competencies. Here, we turn to the issue of professional readiness of high school teachers. On the one hand, we mean the humanitarian basis of the modern teacher (development of his/her spiritual world, intellectual abilities and knowledge, formation of the value sphere). On the other hand, it is a question of the teacher's possession of modern educational technologies (for example, technologies for the development of multimedia teaching materials, technologies for monitoring and determining academic integrity, technologies for designing assessment materials, technologies for operating tools and interaction services in online learning, etc.). It is obvious that the gravity of professional requirements for a modern university teacher raises the issue of motivation and stimulation of the teaching staff to self-improvement. This task has both a social (as facilitated by the society) and individual dimension (in which way the personality of the teacher can contribute to it). This leads to the following problematic questions: How to provide professional training of a teacher with an innovative type of thinking and a formed value sphere? What incentives 
Yurii PELEKH. Urgent issues and modern challenges of higher education

PROBLEMS

OF EDUCATION

IN THE $21^{\text {st }}$ CENTURY Vol. 78, No. 5,2020

672

should the society (the state) offer that would help increase the quality of human resources in higher education? How to increase the level of personal motivation of a high school teacher to professional growth?

It is impossible not to pay attention to the problems of organization of the modern educational process. We should note that modern pedagogical science considers as an axiom the need for interactive teaching methods in higher education. Such methods help to increase the efficiency of the educational process and, at the same time, to ensure the development of the above-mentioned intellectual abilities and creativity, taking into account the individual characteristics of students. On the other hand, the modern realities of the globalized world, which is difficult to imagine without networking with its endless online interaction services, create many new educational opportunities to stimulate cognitive activity and active independence of students in the educational process. Paradoxically, the social distance issue has come in handy here; for reasons of self-preservation, it dictates the need to develop and attract interactive online learning technologies based on a personal-activity approach (Lytvyn et al., 2019). At the same time, this does not mean a complete abandonment of in-class learning. Therefore, we need to address the following questions: What should the ratio of online learning and in-class learning technologies in the educational process be? How does the use of these technologies correlate with the requirements for professional training of specific specialties? What should the content of these two types of training be?

An indisputable problem for higher education is the reduction of its social role, the loss of the status of a social leader. In other words, the voice of the academic community is often ignored. According to a special study (UNEP, 2012) conducted under the auspices of the United Nations "21 Issues for the 21st Century", the current level of interaction between politics and academia is inadequate to the existing problems, which makes it impossible to develop effective solutions to global problems. Thus, modern civilization is characterized by a number of crises: the social and economic crisis (inhibition of global economic growth and increasing disparity between the rich and the poor), the environmental crisis (in all possible manifestations), the crisis of classical forms of government in the globalized world, the crisis of democratic institutions, which are increasingly falling victim to manipulative populism. It is significant that in individual countries the level and depth of these problems are smaller, which can be explained by the higher social status of education and more active participation of academic community (faculty and students) in public life. Therefore, the issue of promotion of higher education, its opportunities, traditions and values is becoming especially relevant now.

Solution of the above-mentioned problems and related issues will contribute to the reform of higher education, its progress. Moreover, it will facilitate the formation of not only personal but also social qualities, providing an effective platform for personal and collective development, common and individual interests, rights and responsibilities.

\section{References}

Lytvyn, A., Lytvyn, V., Rudenko, L., Pelekh, Y., Didenko, O., Muszkieta, R., \& Zukow, W. (2019). Informatization of technical vocational schools: Theoretical foundations and practical approaches. Education and Information Technologies, 25, 583-609. https://doi.org/10.1007/s10639-019-09966-4

UNEP, 2012. 21 Issues for the 21st Century: Result of the UNEP Foresight Process on Emerging Environmental Issues. In Alcamo, J., \& Leonard, S. A. (Eds.). United Nations Environment Programme (UNEP), (pp. 56). Nairobi, Kenya. https://doi.org/10.13140/RG.2.2.22054.32323 
Yurii PELEKH. Urgent issues and modern challenges of higher education

PROBLEMS

OF EDUCATION

IN THE $21^{\text {st }}$ CENTURY

Vol. 78, No. 5, 2020

673

Received: August 31, 2020

Accepted: October 02, 2020

Cite as: Pelekh, Y. (2020). Urgent issues and modern challenges of higher education. Problems of Education in the $21^{\text {st }}$ Century, 78(5), 671-673. https://doi.org/10.33225/pec/20.78.671

Yurii Pelekh

PhD, Professor, Vice-rector, Rivne State University of Humanities, Rivne, Ukraine.

E-mail: pelekhyurii@ukr.net

Website: http://www.rshu.edu.ua/

ORCID: https://orcid.org/0000-0002-1737-4557 